https://www.scilook.eu/index.php/slif/article/view/slif19-01-013 DOI: 10.30888/2415-7538.2020-19-01-013

UDC 637.146.3

\title{
THE USE OF OAT BETA-GLUCANS IN THE DAIRY INDUSTRY: AN OVERVIEW AND ASSESSMENT OF OPPORTUNITIES IN YOGURT TECHNOLOGY
}

\author{
Qu Xiaoqing \\ PhD Student of food technology \\ ORCID: 0000-0003-3340-7336, \\ Ju. Nazarenko \\ Can. Of Techn. Sc., the Head of Department \\ ORCID: 0000-0003-4543-0090, \\ Sumy National Agrarian University, \\ Herasyma Kondratjeva str., 160, Sumy, Ukraine, 40021 \\ Li Bo \\ School of Food Science as prof. \\ ORCID: 0000-0003-4543-0090 \\ Henan Institute of Science and Technology, \\ Xinxiang, PR China, 453000
}

\begin{abstract}
Yogurt has many beneficial influences on human health, including therapeutic, nutritional, probiotic effects, etc. There has been an increasing interest in fortification of yogurt with different kinds of ingredients to further improve added nutritional benefits to human health. Oat $\beta$-glucans consists mainly of the linear polysaccharide $(1 \rightarrow 3),(1 \rightarrow 4)-\beta$-D-glucans. It is a valuable functional ingredient with various properties, including stimulation of the immune system, reduction of blood cholesterol level, reduction in the incidence of cancer, cardiovascular diseases, diarrhea and osteoporosis, etc. These properties lead to the use of $\beta$-glucans into various food systems and have important implications in human health. This review focuses on the fortification of yogurt with oat $\beta$-glucans. Incorporation of oat $\beta$-glucans into yogurt showed that the physical and textural properties of yogurt can be largely modified due to phase separation between $\beta$-glucan and milk proteins. In some cases, incorporation of low levels of oat $\beta$-glucans into fermented milk products could improve the probiotic viability and stability of some bifidobacteria strains during cold storage. In summary, addition of adequate amounts of oat $\beta$-glucans is important as it may affect the quality, rheological properties acidification, gelation kinetics and microbiological properties of yoghurt.
\end{abstract}

Key words: oat $\beta$-glucans; yogurt; property; fortification

It is generally believed that active intake of dietary fiber has a positive impact on the overall state of the human body. The application of dietary fiber in a variety of foods has attracted the attention of food professionals. Barley and oats, especially oat $\beta$-glucans, have attracted much attention due to their high content of soluble non starch polysaccharides (fibrous substances). Meanwhile, oat $\beta$-glucans (OG) is one of the most studied non starch polysaccharides. The structure, occurrence, origin of OG and its positive physiological effects on cardiovascular system. This paper introduced the related research of $O G$ as a functional component of fermented dairy products.

\section{Application of dietary fiber in yoghurt}

Yogurt is the most popular dairy product in the world [1]. Yogurt is rich in essential amino acids, vitamins and minerals, but does not contain fiber. At present, when dietary fiber is added to yogurt as a functional component and nutritional food, it can achieve a variety of functions. Tseng A \& Zhao y added grape pomace as 
antioxidant dietary fiber to yogurt and salad dressing to improve nutritional value and storage resistance [2]. Espírito-Santo, A.P, Lagazzo A, Sousa A, et al. studied the effect of adding passion fruit fiber to probiotic yogurt on rheology, spontaneous whey separation, microstructure and sensory characteristics was studied. The results showed that the apparent viscosity of yogurt made by Lactobacillus fermentation increased. The micrograph of freeze dried yogurt was produced by SEM. Compared with the control sample, it is more dense [3]. Hayaloglu \& Ali, Adnan et al. Studied the effects of pumpkin fiber (PF) on the physicochemical, microbial, rheological and microstructure of low-fat yogurt samples during storage. The results showed that the yoghurt with PF had lower synthesis rate and higher viscosity structure than the control. SEM images showed that more filamentous structures and dense reticular structures were observed in the samples added PF, and these structures increased with the increase of PF level. The results showed that PF improved the physical quality and texture properties of half fat yogurt [4]. Hashim IB,Khalil AH \& Afifi HS produced an acceptable product with 3\% jujube fiber fortified yoghurt with potential health benefits [5].

Previous studies have shown that dietary fiber can change the basic quality parameters of yogurt, such as physicochemical, texture, microorganism, nutrition, functional and sensory properties. As these changes have both advantages and disadvantages, it is necessary to select the appropriate fiber at a precise level. It is a hot topic to select the appropriate kind and amount of dietary fiber added to yoghurt. OG has been widely concerned because of its structure and functional properties.

\section{Structural and functional properties of oat $\beta$-glucans (OG)}

Oat $\beta$-glucans (OG), cell wall polysaccharides of cereal grains, are recognized worldwide as functional bioactive ingredients. Health benefits of oat-based food products are attributed to the OG. It is a linear homopolysaccharide of consecutively linked (1/4)- $\beta$-D-glucosyl residues in oligomeric segments that are separated by single (1/3)-bonds along the polymer chain backbone; i.e., its structure consists mostly of cellotriosyl and cellotetraosyl oligomers interlinked via $\beta-(1 / 3)$ glycosidic linkages. Furthermore, OG have all the health benefits of soluble dietary fibers, including the reduction of blood serum cholesterol and the regulation of post-prandial blood glucose levels [6].

Both the US Food and Drug Administration (US FDA) and the European Food Safety Authority (EFSA) have authorized health claims, according to which OG ingestion leads to the reduction of blood plasma cholesterol concentrations and heart disease risk with a daily consumption of $3 \mathrm{~g}$ of $\beta$-glucan (a minimum of $0.75 \mathrm{~g}$ per serving) originating from oat-formulated products that include oat bran, rolled oats and whole oat flour. Fortification of foods with OG is of great interest. Many foods, such as pasta, tea cakes, muffins, bread, and beverages have been fortified with OG [7-10].

The potential use of the neutral polysaccharide in food products has been proposed based on its rheological characteristics that can provide desirable textural properties to food products, such as viscosity enhancement and gelling properties. The rheological characteristics appear to be related to the concentration, molecular weight, and structural features of these indigestible polysaccharides [11]. 


\section{Application of oat $\beta$-glucans in yoghurt}

There has been an increasing interest in fortification of yogurt with different kinds of ingredients to further improve added nutritional benefits to health. Several studies have been reported on the influence of some ingredients like proteins, polysaccharides and metal ions [12;13]. Among these functional foods, much attention is paid especially to the probiotic products and food containing OG. On the other hand, incorporation of cereal $\beta$-glucans into milk or milk protein derived gels, through acidification with glucono-d-lactone (GDL) or by bacteria fermentation, showed that their physical and textural properties can be largely modified due to phase separation between $\beta$-glucans and milk proteins [14]. The changes in physical and textural properties seem to be governed by the concentration and the structural features of the added polysaccharide. On the other hand, gut-health benefits associated with probiotics can be complemented by the heart-health benefits of $\beta$ glucan in a yogurt system to provide a doubly healthful product.

Previous studies suggest a prebiotic action of cereal $\beta$-glucans on some Lactobacillus species $[15 ; 16]$. Some studies indicate that incorporation of low levels (up to $0.5 \%$ ) of oat and barley $\beta$-glucans into fermented milk products have no adverse effects on growth of two yogurt starter cultures (SCs) each consisting of Streptococcus thermophilus and Lactobacillus delbrueckii subsp. bulgaricus and even improved the probiotic viability and stability of some bifidobacteria strains during cold storage [17].

OG can be used on the development of cereal-based functional dairy products (such as yoghurt) with sufficient viability and acceptable sensory characteristics. Vasiljevic and others studied the growth and metabolic activity of probiotic organisms in yogurt and reported that addition of OG resulted in improved probiotic viability and stability [18]. Rosburg et al. suggested that OG imparted a protective effect on bifidobacteria strains (for example, B. longum) in yogurt under prolonged cold storage at $4^{\circ} \mathrm{C}$ [19]. Ozcan et al. investigated the effects of using dietary fiber barley and oat $\beta$-glucan as a prebiotic on the viability of Bifidobacterium bifidum in probiotic yoghurt and properties of yogurt during storage. It was found that the survival of $\mathrm{B}$. bifidum was within biotherapeutic level $(>7 \log \mathrm{cfu} / \mathrm{g})$ due to the prebiotic effect of barley and oat based $\beta$-glucan. The addition of $\beta$-glucan to yogurt significantly affected physicochemical properties of yogurts, including $\mathrm{pH}$, titratable acidity (LA \%), whey seperation, color $\left(\mathrm{L}^{*}, \mathrm{a}^{*}, \mathrm{~b}^{*}\right)$ and sensorial properties [20].

In order to meet the nutrient guidelines, adequate amounts of OG should be added to yogurt to have added nutritional benefits. Brennan and Tudorica (2008) found that $0.5 \% \beta$-glucans addition improved serum retention and viscoelastic nature of yogurt [21]. Singh et al. reported the effect of OG on the fermentation of set-style yogurt. It was found that $\mathrm{OG}$ could be added to yogurt up to $0.3 \%$, which meets the FDA guidelines of $0.75 \mathrm{~g} \beta$-glucan/serving for a health claim, resulting in yogurts with quality characteristics similar to the control yogurt. However, higher contents of OG retarded the fermentation process with noticeable difference in the characteristics of the yogurt. As observed by phase-contrast microscope, it was found that OG formed aggregates with casein micelle and did not form phase-separated domains [22]. 
Lazaridou et al. studied the impact of cereal $\beta$-glucans $(1.4 \%)$ on acidification, gelation kinetics and microbiological properties of milk products fermented by yogurt starter culture bacteria and/or probiotic strains [23]. Incorporation of purified OG to milk resulted in phase separation between the added polysaccharide and milk proteins and altered the entire gelation process. Fortification of milk with $1.4 \%$ OG retarded the protein aggregation and acidification processes, leading to the formation of significantly weaker gels compared to control formulations. Furthermore, fortification of milk with $\mathrm{OG}$ led to a liquid-like structure at the end of fermentation $(\mathrm{pH}=4.6)$ at $36{ }^{\circ} \mathrm{C}$. Moreover, the probiotic strain of $L$. paracasei exhibited good compatibility with the yogurt starter culture and OG addition enhanced the viability of the probiotic strain in the milk fermented products during cold storage $\left(4{ }^{\circ} \mathrm{C}\right)$.

\section{Future trends}

The influence of the dietary fiber content of oat $\beta$-glucans on the physical, sensory and technological properties of yoghurt is a relevant area and deserves further study. The effect of oat $\beta$-glucans on probiotics in yoghurt under different production conditions requires further study. It is useful to study the effect of the molecular weight and solubility of oat $\beta$-glucans on yogurt, as well as the role of oat $\beta$-glucan in relation to the mass fraction of fat in yogurt. The challenge for food researchers is to develop products that are more beneficial to human health. The use of oat $\beta$-glucans in yogurt is worth exploring for its potential value.

\section{References}

1. Samh, M. M. A. E., Sherein, A. A. D., \& Essam, H. H.. (2013). Properties and antioxident activity of probiotic yoghurt flavored with black carrot, pumpkin and strawberry. International Journal of Dairy ence, 8(2), pp.48-57.

DOI: $10.3923 / \mathrm{ijds} .2013 .48 .57$

2. Tseng, A. , \& Zhao, Y. . (2013). Wine grape pomace as antioxidant dietary fibre for enhancing nutritional value and improving storability of yogurt and salad dressing. Food Chemistry, 138(1), pp.356-365.

DOI: 10.1016/j.foodchem.2012.09.148

3. A.P. Espírito-Santo, Lagazzo, A., Sousa, A.L.O.P. , Perego, P., Converti, A., \& Maricê N.Oliveira. (2013). Rheology, spontaneous whey separation, microstructure and sensorial characteristics of probiotic yoghurts enriched with passion fruit fiber. Food Research International, 50(1):224-231.

DOI: $10.1016 /$ j.foodres.2012.09.012

4. Hayaloglu, Ali, Adnan, Dagdemir, Elif, \& Boran, et al. (2017). The effect of pumpkin fibre on quality and storage stability of reduced-fat set-type yogurt. International Journal of Food ence and Technology, 52(1), pp.180-187.

DOI:10.1111/ijfs.13264

5. Hashim, I. B., Khalil, A. H., \& Afifi, H. S.. (2009). Quality characteristics and consumer acceptance of yogurt fortified with date fiber. Journal of Dairy ence, 92(11), pp. 5403-5407.

DOI: $10.3168 /$ jds.2009-2234

6. Butt, M. S., Tahir-Nadeem, M., Khan, M. K. I., Shabir, R., \& Butt, M. S. . (2008). Oat: unique among the cereals. European Journal of Nutrition, 47(2), pp.68- 
79 .

DOI: $10.1007 / \mathrm{s} 00394-008-0698-7$

7. Man, P., Rimsten, L. , \& Andersson, R. . (2004). Molecular weight distribution of $\beta$-glucan in oat-based foods. Cereal Chemistry, 81(3), pp.356-360.

DOI: 10.1094/CCHEM.2004.81.3.356

8. Tosh, S. M. , Brummer, Y., Miller, S. S. , Regand, A., Defelice, C. , \& Duss, R. , et al. (2010). Processing affects the physicochemical properties of $\beta$-glucan in oat bran cereal. Journal of Agricultural \& Food Chemistry, 58(13), pp.7723.

DOI: $10.1021 / \mathrm{j} 904553 \mathrm{u}$

9. Moriartey, S., Temelli, F. , \& Vasanthan, T. . (2010). Effect of formulation and processing treatments on viscosity and solubility of extractable barley $\beta$-glucan in bread dough evaluated under in vitro conditions. Cereal Chemistry, 87(1), pp.65-72.

DOI: 10.1094/CCHEM-87-1-0065

10. Wood, P. J. . (2007). Cereal $\beta$-glucans in diet and health. Journal of Cereal ence, 46(3), pp.230-238.

DOI: $10.1016 /$ j.jcs.2007.06.012

11. Lazaridou, A. , \& Biliaderis, C. G. . (2007). Molecular aspects of cereal $\beta$ glucan functionality: physical properties, technological applications and physiological effects. Journal of Cereal ence, 46(2), pp.101-118.

DOI: $10.1016 /$ j.jcs.2007.05.003

12. Marta, Guzmán-González, Federico, Morais, and, \& Lourdes, et al. (2000). Influence of skimmed milk concentrate replacement by dry dairy products in a lowfat set-type yoghurt model system. use of caseinates, co-precipitate and blended dairy powders. Journal of the Science of Food \& Agriculture. 80(4), pp. 433-438.

DOI: 10.1002/(SICI)1097-0010(200003)80:4<433::AID-JSFA545>3.0.C

13. Aportela-Palacios, A., Sosa-Morales, M. E., \& J.F. VÃ $\square$ LEZ-RUIZ. (2005). Rheological and physicochemical behavior of fortified yogurt, with fiber and calcium. Journal of Texture Studies, 36(3), pp.333-349.

DOI: $10.1111 / \mathrm{j} .1745-4603.2005 .00020 . \mathrm{x}$

14. Kontogiorgos, V., Ritzoulis, C. , Biliaderis, C. G. , \& Kasapis, S. . (2006). Effect of barley $\beta$-glucan concentration on the microstructural and mechanical behaviour of acid-set sodium caseinate gels. Food Hydrocolloids, 20(5), pp.749-756.

DOI: 10.1016/j.foodhyd.2005.07.008

15. Gerhard, D. , Mario, H. , Erich, G. , \& Wilhelm, F. . (0). Dietary fiber-rich barley products beneficially affect the intestinal tract of rats. Journal of Nutrition, 132(12), pp.3704-3714.

DOI: $10.1093 / \mathrm{jn} / 132.12 .3704$

16. Snart, J., Bibiloni, R., Grayson, T. , Lay, C. , Zhang, H. , \& Allison, G. E. , et al. (2006). Supplementation of the diet with high-viscosity beta-glucan results in enrichment for lactobacilli in the rat cecum. Applied \& Environmental Microbiology, 72(3), pp.1925-1931.

DOI: 10.1128/AEM.72.3.1925-1931.2006

17. Gee, V. L., Vasanthan, T., \& Temelli, F.. (2007). Viscosity of model yogurt systems enriched with barley $\beta$-glucan as influenced by starter cultures. International Dairy Journal, 17(9), pp.1083-1088. 
DOI: $10.1016 / j$.idairyj.2007.01.004

18. Vasiljevic, T., Kealy, T., \& Mishra, V. K.. (2007). Effects of $\beta$-glucan addition to a probiotic containing yogurt. Journal of Food Science, 72(7), pp. C40511 .

DOI: $10.1111 / \mathrm{j} .1750-3841.2007 .00454 . \mathrm{x}$

19. Rosburg, V., Boylston, T., \& White, P.. (2010). Viability of bifidobacteria strains in yogurt with added oat beta-glucan and corn starch during cold storage. Journal of Food ence, 75(5), pp.C439-C444.

DOI: $10.1111 / \mathrm{j} .1750-3841.2010 .01620 . \mathrm{x}$

20. Ozcan, T., \& Kurtuldu, O.. (2014). Influence of dietary fiber addition on the properties of probiotic yogurt. International Journal of Chemical Engineering and Applications, 5(5), pp.397-401.

DOI: 10.7763/IJCEA.2014.V5.417

21. Brennan, C. S., \& Tudorica, C. M.. (2010). Carbohydrate-based fat replacers in the modification of the rheological, textural and sensory quality of yoghurt: comparative study of the utilisation of barley beta-glucan, guar gum and inulin. International Journal of Food ence \& Technology, 43(5), pp.824-833.

DOI: $10.1111 / \mathrm{j} .1365-2621.2007 .01522 . x$

22. Singh, M., Kim, S., \& Liu, S. X.. (2012). Effect of purified oat $\beta$-glucan on fermentation of set-style yogurt mix*. Journal of Food ence, 77(8), pp. E195-E201.

DOI: $10.1111 /$ j.1750-3841.2012.02828.x

23. Lazaridou, A., Serafeimidou, A., Biliaderis, C. G., Moschakis, T., \& Tzanetakis, N.. (2014). Structure development and acidification kinetics in fermented milk containing oat $\beta$-glucan, a yogurt culture and a probiotic strain. Food Hydrocolloids, 39(aug.), pp.204-214.

DOI: 10.1016/j.foodhyd.2014.01.015 